\title{
3
}

\section{Form and Performance: The Relations of Melody, Poetics, and Rhythm in Dhalwangu Manikay}

\author{
Peter G. Toner
}

Stephen Wild's 1984 article with Margaret Clunies Ross, 'Formal Performance: The Relations of Music, Text and Dance in Arnhem Land Clan Songs' (Clunies Ross and Wild 1984), marked something of a watershed in Aboriginal music research generally and in Arnhem Land music research in particular. For one thing, this was the first article on Australian Aboriginal music to appear in the discipline's flagship journal for more than 15 years (since his own article, co-authored with Elizabeth May, on Aboriginal music on the Laverton Reservation (May and Wild 1967)), despite a steady stream of primary research. More importantly, it was a demonstration of the necessity to adopt an analytical approach that considered music not as a separate realm of human experience, but rather as deeply interconnected with dance and song texts as an integrated whole (and, as a result, it also represented a significant example of interdisciplinary collaboration). Finally, it represented the midpoint of Stephen Wild's long-term engagement with ethnomusicological and ethnographic materials on Arnhem Land music - a second research area for him after his own important work on Warlpiri music, but one to which he adapted effectively and made important contributions (Clunies Ross and Wild 1982; Wild 1986). It is certainly the case that postgraduate 
research on Arnhem Land music from the mid-1980s onward had to reflect deeply on the insights contained in 'Formal Performance' and to respond accordingly.

'Formal Performance' exemplified an approach to the analysis of Aboriginal ritual performances that took music, song texts, dance, and ritual context as elements that were each intricately structured in their own terms and that could yield rewarding and worthwhile analyses. What this article more powerfully demonstrates, however, is that a combined analysis, juxtaposing and comparing these co-performed elements when they were contiguous in time and space, is even more powerful as an analytical tool. What becomes abundantly clear is that Anbarra ritual performances are subject to clearly enacted structural principles that are themselves the result of deep thinking, careful coordination, and virtuosic talent.

In this chapter, I use Clunies Ross and Wild's article as the catalyst for an analysis of the complex relationships between melody, poetics, and rhythm in performances of manikay by Dhalwangu performers in Gapuwiyak, Northern Territory. As was the case for Clunies Ross and Wild's Anbarra performers of the Djambidj song series, Dhalwangu musical and poetic form is influenced by the aesthetics and formal requirements of dance. Notably, any given song subject may be performed in a number of different ways that are rhythmically, poetically, and contextually distinctive, which I have called 'song versions'. As Clunies Ross and Wild noted for the differences between 'formal' and 'elaborate' bunggul among the Anbarra, the differences between different 'versions' of Dhalwangu song subjects are based on a complex amalgam of dance aesthetics, poetic narrative development, clapstick rhythm, melodic phrasing, and the requirements of the underlying ritual context. An extended analysis of Dhalwangu manikay using the concept of 'song versions' reveals the existence of a distinctly Dhalwangu musical theory that underlies the performative decisions made in any given musical context. Additionally, it pays homage to the approach to Aboriginal music analysis to which Stephen Wild made such an important contribution.

\section{The analysis of the Djambidj song series}

Clunies Ross and Wild were interested in examining the variable rules, and the variable but consistent structures, that combined to make these performances 'formal' (1984: 209), recognising that the performance 
context in which songs are performed, and the intersection of the media of melody, rhythm, text, and dance, can result in variability within a recognised range. They examined performances of a song series called Djambidj, performed by the Anbarra people whose traditional country lies near the mouth of the Blyth River. Their analysis revealed that each performance element had its own established patterns, deployed in particular ways depending on the context. A subset of seven Djambidj song subjects is performed, as an adjunct to the larger ritual context, in evening performances as a form of entertainment. Two distinctive styles of dance emerged from their analysis. The first is the 'elaborate' bunggul, which consists of 'a series of dance sequences which continue through a sequence of song verses' (ibid.: 213), and which includes the unique dance patterns of circling and the formation of long lines of dancers at certain points in the performance. The second style is referred to as the 'formal' bunggul, in which the dance coincides with a single song 'verse' (item), which is characterised by a movement of the dancers back and forth across the dance ground, and which may include the dance pattern they call a 'high leg stamp' (ibid.: 213-14). The two subjects they examine that have an 'elaborate' dance form are also performed in the 'formal' style.

Clapstick rhythm is also an important element of their analysis. They note that each song subject has both a main clapstick pattern and variant patterns that mark structural divisions, and that a set of main plus variant patterns is used for several verses of each subject, with the exception of Spangled Grunter that has two sets of main plus variant patterns (ibid.: 215). They further note that a main clapstick pattern in one song subject may be the variant pattern in another subject, yielding up a 'patchwork' quality of stylistic components used in different combinations (ibid.). They identify four main clapstick patterns in the performances that they analyse.

1 Clunies Ross and Wild use the term 'verse' to describe the level of musical structure I refer to as a 'song item'-i.e. a distinct musical and poetic rendition of a song, bounded on either end by silence, conversation, etc. Their use of the term 'verse' in that article should not be confused with the concept of a 'song version', which I use to describe a number of song items or 'verses' of the same song subject, and that share in common rhythmic and poetic features. Confusingly, in an earlier article on the same musical tradition, Clunies Ross writes that 'the verse may be defined as a group of lines which is recognised by the singer and his audience as having a distinct form, both verbal and musical, but which belongs to a larger entity, the song-item, the latter consisting of a variable number of musically and thematically related strophes' (1978: 133). There is, unfortunately, little consensus on nomenclature in Arnhem Land ethnomusicology; Greg Anderson (1995) uses the terms 'song item', 'song subject', and 'song series', while Steven Knopoff (1992) uses 'song verse', 'song subject', and 'song series'. 
Melodically, their analysis also revealed two types of song 'verses'. What they call 'Type A' verses are used in song subjects that can accompany both 'formal' and 'elaborate' bunggul, are identifiable by sections of regular length that always consist of three phrases (but the phrases themselves are of irregular length), use melodies consisting of two tones, and have complex rhythmic relations between text and melody. 'Type B' verses, on the other hand, only accompany 'formal' bunggul, are characterised by sections that are irregular in length and in number of phrases (but whose phrases themselves are always of regular length), usually use three-tone melodies, and have a simple rhythmic relation between text and melody (ibid.: 216).

Textually, Clunies Ross and Wild note some variability in the way song textual phrases are deployed in 'Type A' and 'Type B' verses/song items. In the former, they note that the textual phrases generally conform to melodic phrases, but with a notable prolongation of final syllables to accommodate sustained tones in the melody and to mark the end of a textual phrase; additionally, in 'Type A' verses/song items, the ends of vocal sections are further marked by a final $-m$ sound added to the final syllable of the text. On the other hand, 'Type B' verses/song items are more variable in accommodating cues for dancers at different points in the structural sequence (ibid.: 218).

Overall, Clunies Ross and Wild demonstrate in their analysis that there is a complex relationship between clapstick rhythm, melody, song texts, and dance in Arnhem Land songs, and that the distinctive patterns of each must be carefully aligned with all of the others. Two distinctive styles of dance are accompanied by particular uses of melody, song-text phrases of variable number and length, and clapstick patterns marking structurally important divisions to accommodate dancers. Whether a performance is sung on its own or as an accompaniment to dance exerts a notable influence on other musical and textual elements, demonstrating the necessity for considering the impact of dance on the structure of Arnhem Land music.

\section{Anbarra and Dhalwangu manikay compared}

Despite a range of similarities, it is impossible simply to map Clunies Ross and Wild's analysis onto the music of the Dhalwangu people of Gapuwiyak, with whom I worked. Most significantly, my own detailed 
analyses of Dhalwangu songs were all of performances that did not accompany dance, although certain inferences can be made based on my larger sample of recordings. Dhalwangu musicians did recognise two basic styles of manikay performances: bunggulmirr (with dance), accompanying dance performances during rituals; and ngaraka (bones), which were performed with only singers and a didjeridu accompanist, and could occur in ritual contexts, for entertainment, or for the specific purpose of recording. My analysis of Dhalwangu manikay, however, indicates that certain musical principles structured to accommodate dance performances are also used in non-danced performances. This underscores the significance of dance emphasised by Clunies Ross and Wild.

Another challenge in comparison relates to rhythmic diversity. Clunies Ross and Wild identified four main clapstick patterns in the seven Djambidj subjects that they analysed. My own analysis of the recording Djambidj: An Aboriginal Song Series from Northern Australia (Butler and Wild 1981) confirms this finding. In that recording (an elicited one recorded in Canberra, with only singing and no dancing), I identified four repeating clapstick patterns making up the 'main' pattern:

- a repeating quarter-note pattern (or 'singles' (Moyle 1978: 8));

- a repeating pattern of 'separated doubles'2 (ibid.);

- a repeating pattern of one separated double followed by one single;

- a repeating pattern of one separated double followed by two singles.

The same four repeating patterns accounted for all of the 'variant' patterns on the recording. I also identified a small number of rhythmic components used to separate 'main' and 'variant' patterns, or to terminate song items: either one, two, or three 'singles' that did not repeat; a 'separated double' followed by either one or two 'singles'; a 'separated double' followed by a 'single', repeated only once; and two 'separated doubles' followed by two 'singles'. So, the Djambidj repertoire available for analysis in that recording seems to be one that features quite a small number of rhythmic components combined in a relatively small number of ways.

2 Moyle (1978: 8) describes 'doubles' as percussive beating sounds that are twice as fast as 'singles', while 'separated doubles' are 'doubles' with a short gap of silence after each pair. She illustrates 'separated doubles' with a music notation depicting a repeating triplet figure, each with two eighth notes and an eighth rest. 
In contrast, the entire repertoire of Dhalwangu clapstick patterns consists of a much larger number of rhythmic components. My analysis of six complete performances of five different song series revealed a total of 43 unique rhythmic components, although about two dozen of these feature in only one or two song subjects. The apparently greater diversity of Dhalwangu clapstick rhythms may be due to the fact that I analysed five different song series, whereas Clunies Ross and Wild examined only one performed by the Anbarra (although elsewhere they also examined a second song series, called Goyulan).

A final analytical difference pertains to the range of rhythmically and poetically distinctive ways in which each song subject may be performed, as well as the nomenclature used to discuss song subjects and their musical identities. My analysis of the Djambidj recording indicates that some song subjects are performed with one rhythmic setting only, while others are performed in two different rhythmic settings. In Dhalwangu music, the performance of two different song versions of each song subject (to be discussed below) is almost always a bare minimum, and some song subjects are performed in five or more distinctive song versions (each of which is a distinctive rhythmic setting, but also includes distinctive poetic patterns as well). Each rhythmically and poetically distinctive version of a song subject is identified as belonging to one of six different categories that are used to conceptualise the entire Dhalwangu repertoire. Clunies Ross and Wild's 'elaborate' and 'formal' distinction in Anbarra performance appears similar in some ways to different Dhalwangu 'song versions': in the bulnha (slow) and yindi (big or important) versions, there is a non-metrical relationship between clapstick rhythm, song text, melody, and dance movements (similar to the 'complex' relationship between text and melody noted by Clunies Ross and Wild in 'Type A' verses/ song items), whereas in all other versions there is a metrical relationship between these (as in Clunies Ross and Wild's simpler 'Type B' verses/ song items). Additionally, they note a third type of Anbarra verse/song item, 'Type C', which seems clearly to correspond to the yindi version of Dhalwangu songs.

So, while there are some suggestive hints as to more direct comparisons between Anbarra and Dhalwangu music that might be possible, in this chapter I will adopt an approach that is indebted to Clunies Ross and Wild in a more general way. The distinctive contribution of their important article lies in its recognition of structurally consistent (although variable) patterns of melody, rhythm, text, and dance, and the fact that each of 
these different performance elements (especially dance) exerts a significant influence on the others. With these insights in mind, I turn now to a more detailed discussion of different versions of Dhalwangu songs, in an effort to highlight a similarly patterned interconnection between distinctive elements.

\section{Dhalwangu song versions}

I developed the concept of the 'song version' as a way to recognise a basic fact during my fieldwork in Gapuwiyak, working most closely with Dhalwangu musicians. When sitting in performances, I would frequently ask men sitting near me to identify the song being performed and would be told, for instance, 'watjbalnga' (wild rooster). Paying careful attention to the music, when I noted a change in clapstick rhythm, I would again ask my interlocutor to identify this new song, only to be told 'it's still watjbalnga'. Only after several obvious rhythmic changes (each associated with three to six song items) would I finally be told that the performance had now moved on to the next song subject, mokuy (spirit). This progression through the structure of a musical performance is represented in an idealised form in Figure 1.

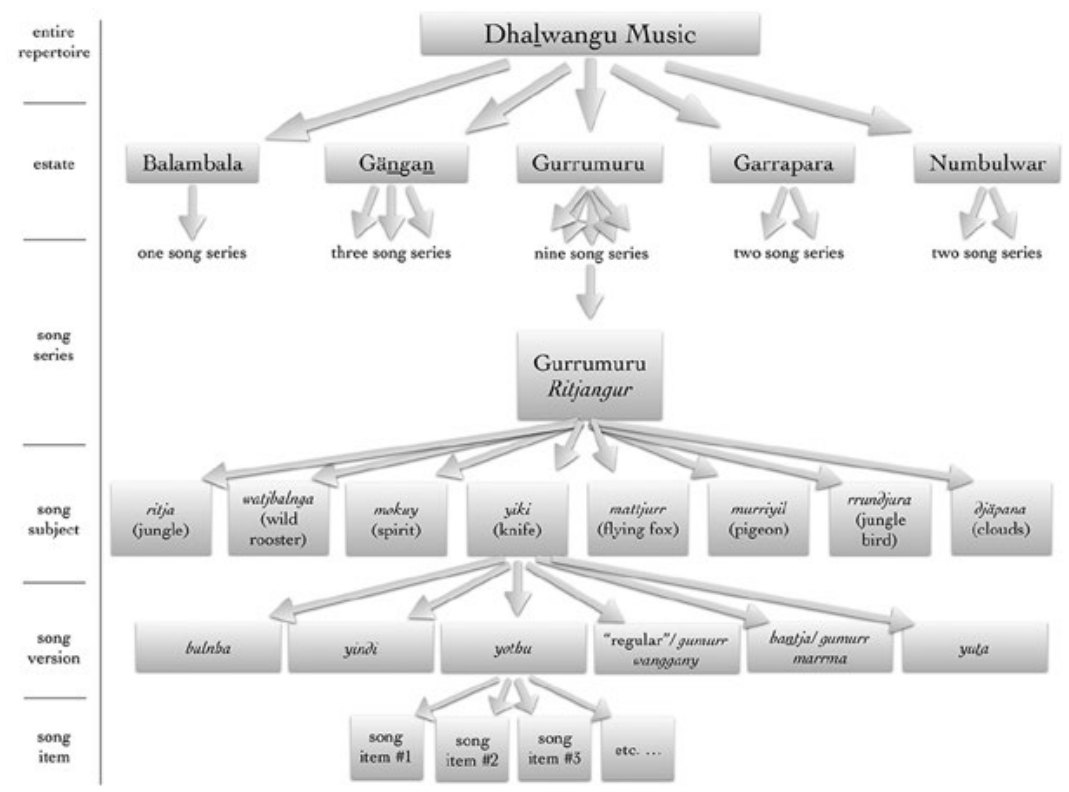

Figure 1. Dhalwangu musical structure 
The entirety of the Dhalwangu repertoire is, first of all, divided between five estates, each of which has a number of song series associated with it. Each song series is made up of a range of song subjects (usually between one and two dozen), each depicting an animal, plant, meteorological phenomenon, or spirit being associated with the estate and the particular narrative being developed concerning that estate. Each of these song subjects is performed in a number of different song versions corresponding to one of six different named categories; these are most obviously distinguished by clapstick rhythm, but also by the poetic imagery utilised by the singers, and sometimes by the particular ritual contexts in which they are used. Finally, each version is performed as a separate musical/ poetic/choreographed unit known as a song item, lasting from 20 seconds to perhaps two minutes (depending on the version in question). It is the level of musical structure known as the song version that has been underrecognised and under-analysed until relatively recently in the Arnhem Land ethnographic literature, and yet it seems to be the level of structure where the integration of music, text, and dance identified by Clunies Ross and Wild is most apparent.

The sequence of versions of any given song subject is normally very consistent, although not all versions of a subject need to be performed in any given context, and not all subjects have every named version. If a song subject has a bulnha (slow) version and the singers wish to use it on a given occasion, it is always performed first, followed by the yindi (big or important) version (again, if the subject has a yindi version, and if the singers choose to use it). All song subjects have a version referred to as gumurr wanggany (chest one), which is normally followed by a version called gumurr marrma (chest two). These are terms that refer specifically to bunggulmirr (with dance) performances, particularly the common performance convention of providing dancers with at least two rhythmically distinct versions of a song subject to dance to, and are used to signify 'number one' and 'number two'. In ngaraka performances that do not accompany dance, the terms gumurr wanggany and gumurr marrma may still be used, although it is common for the former version to simply be referred to by the name of the song subject, and the latter version to be referred to as bantja (arm). Another category label, yothu (small or child), seems only to be used as an additional term to refer to whatever version immediately follows a yindi version (i.e. 'big $\rightarrow$ small' or 'mother $\rightarrow$ child'), whether it be a 'regular'/gumurr wanggany version or a bantjal gumurr marrma version (indeed, singers were inconsistent about whether 
they even used the term yothu or not). Finally, a version known as yuta (new) is often used as the last version of a subject before proceeding on to the next.

To illustrate these concepts further, Figure 2 shows the entire sequence of a performance of the Gurrumuru Wängangur song series, consisting of a total of 18 song subjects. With one exception, each song subject is performed in multiple different song versions, and each version of a song subject is performed several times. The sequence of song versions always proceeds in the order: bulnha $\rightarrow$ yindi $\rightarrow(\text { yothu })^{3} \rightarrow$ 'regular'/ gumurr wanggany $\rightarrow$ bantjalgumurr marrma $\rightarrow$ yutata, although very few performances of a song subject would use all six named song versions.

\begin{tabular}{|l|l|}
\hline Song subject & Song version (song items) \\
\hline matha (talking) & 'regular'/gumurr wanggany (song items 1-10) \\
\hline & bantja/gumurr marrma (song items 11-18) \\
\hline yiki (knife) & bulnha (song items 19-20) \\
\hline & bulnha/yindi (song item 21) \\
\hline & yindi (song items 22-23) \\
\hline & yothu (song items 24-26) \\
\hline & bantja/gumurr marrma (song items 27-29) \\
\hline & yuta (song items 30-31) \\
\hline bulnha (song items 32-36) \\
\hline & 'regular'/gumurr wanggany (song items 37-40) \\
\hline & bantja/gumurr marrma (song items 41-42) \\
\hline & yuta \#1 (song items 43-45) \\
\hline & yuta \#2 (song items 46-47) \\
\hline & 'regular'/gumurr wanggany (song items 48-54) \\
\hline marrtji (walking) & 'regular'/gumurr wanggany (song items 55-57) \\
\hline nhina (sitting down) & bantja/gumurr marrma (song items 58-62) \\
\hline & 'regular'/gumurr wanggany (song items 63-65) \\
\hline manydjarrka (cloth) & bantja/gumurr marrma (song items 66-70) \\
\hline & 'regular'/gumurr wanggany (song items 71-73) \\
\hline yakurr (sleeping) & bantja/gumurr marrma (song items 74-75) \\
\hline & 'regular'/gumurr wanggany (song items 76-78) \\
\hline wurrulul (flies) & bantja/gumurr marrma (song items 79-80) \\
\hline & yuta (song items 81-83) \\
\hline &
\end{tabular}

3 In this performance, the term yothu was only used once, in the song subject yiki. In this case, the progression in the song subject was yindi $\rightarrow$ yothu $\rightarrow$ bantjalgumurr marrma, suggesting that the $y o t h u$ in this case functions as the 'regular' or gumurr wanggany version. 


\begin{tabular}{|c|c|}
\hline Song subject & Song version (song items) \\
\hline \multirow[t]{2}{*}{ dhamburru (drum) } & 'regular'/gumurr wanggany (song items 84-86) \\
\hline & bantja/gumurr marrma (song items 87-88) \\
\hline \multirow[t]{2}{*}{ djuling (mouth organ) } & 'regular'/gumurr wanggany (song items 89-92) \\
\hline & yuta (song items 93-95) \\
\hline \multirow[t]{2}{*}{ dubulu (gambling with cards) } & 'regular'/gumurr wanggany (song items 96-99) \\
\hline & yuta (song items 100-101) \\
\hline \multirow[t]{3}{*}{ nganitji (alcohol) } & bulnha (song items 102-8) \\
\hline & 'regular'/gumurr wanggany (song items 109-10) \\
\hline & bantja/gumurr marrma (song items 111-12) \\
\hline \multirow[t]{2}{*}{ barrundhu (fighting) } & 'regular'/gumurr wanggany (song items 113-14) \\
\hline & yuta (song items 115-16) \\
\hline \multirow[t]{3}{*}{ yiki (knife) } & 'regular'/gumurr wanggany (song items 117-19) \\
\hline & bantja/gumurr marrma (song items 120-21) \\
\hline & bantja/gumurr marrma \#2 (song items 122-23) \\
\hline \multirow[t]{5}{*}{ garrurru (flag) } & bulnha (song items 124-29) \\
\hline & 'regular'/gumurr wanggany (song items 130-32) \\
\hline & bantja/gumurr marrma (song items 133-34) \\
\hline & yuta (song items 135-40) \\
\hline & yuta \#2 (song items 141-44) \\
\hline \multirow[t]{2}{*}{ ngatha (rice) } & 'regular'/gumurr wanggany (song items 145-49) \\
\hline & yuta (song items 150-51) \\
\hline \multirow[t]{3}{*}{ watjbalnga (wild rooster) } & bulnha (song items 152-56) \\
\hline & bantja/gumurr marrma (song items 157-59) \\
\hline & yuta (song items 160-61) \\
\hline \multirow[t]{3}{*}{ dirrmala (north wind) } & 'regular'/gumurr wanggany (song items 162-64) \\
\hline & bantja/gumurr marrma (song items 165-67) \\
\hline & yuta (song items 168-70) \\
\hline
\end{tabular}

Figure 2. Song subjects and song versions of the Gurrumuru Wängangur song series

Source: Recorded by the author on 19 October 1996 in Gapuwiyak

Certain musical features are typical of, but not necessarily exclusive to, these categories that I have called song versions. The bulnha always uses a very slow, non-metrical clapstick pattern, with a non-metrical relationship between the clapsticks and the vocals, and with a smooth and unadorned didjeridu accompaniment. The yindi always uses a very fast, non-metrical clapstick pattern, with a non-metrical relationship between the clapsticks and the vocals, and with a smooth and unadorned didjeridu accompaniment. In fact, vocal melody and didjeridu accompaniment may 
be virtually identical in the bulnha and yindi versions of a song subject. All other versions have a steady clapstick beat and a strictly metrical relationship between vocals and clapsticks-in other words, unlike the bulnha or the yindi, the other named versions have a steady rhythmic pulse that provides a relatively tight coordination of melody, rhythm, and dance accompaniment. The yindiversion has a unison 'chorus' that occurs at the end of the main body of a song item, just before the unaccompanied vocal coda; it is a distinctive feature of only the yindi. The yuta version is similarly distinguished by not one, but two unison 'chorus' sections, although the significance of these is not the same as that of the yindi chorus-in the yindi, the chorus usually represents the sound of an important and sacred ancestral being, whereas in the yuta the chorus references a contemporary event that is metaphorically connected to an ancestral song subject (see Knopoff 1992). Certain rhythmic components, like a steady quarternote clapstick beat for an entire song item, are only ever used in gumurr wanggany versions; certain other rhythmic components, like a pattern of 'separated doubles', is only ever used in gumurr marrma and yuta versions.

Song versions, however, are not only distinguished by clapstick rhythms; they are also conceptually and poetically distinctive. The progression from one version of a song subject to another, although marked rhythmically, is also marked poetically, with singers emphasising different aspects of the song subject in a kind of narrative sequence-for example, subsequent versions of the song subject gapu (water) describing the water bubbling up from the ground, then beginning to flow rapidly, then slowing down and turning, before finally becoming calm. Additionally, the different versions of songs are meaningful in different ways. Bulnha versions tend to emphasise a sense of the subject just beginning to reveal itself. Yindi versions, reserved for the most important and sacred song subjects, are said to describe those subjects 'broadly' and make use of likan (elbow) names that condense references to both people and places. The bantja version is used to 'finish off' a subject conceptually, bringing the description of it to a poetic conclusion before moving on to the next subject. Different song versions, therefore, are rhythmically, poetically, and conceptually marked; all of these may relate to the interconnections between music, text, and dance.

The recognition of the level of musical structure that I have called the song version has developed over the past 20 years in Arnhem Land ethnomusicology. As indicated above, there are suggestive passages in Clunies Ross and Wild's work that indicate an awareness of it. Their discussion of song subjects that may be performed in both an 'elaborate' 
and a 'formal' style (1984: 213), as well as their recognition of at least three distinctive 'Types' of 'verses' (ibid.: 216), provided a starting point for further analyses. Greg Anderson's research just to the east of the Anbarra recognised a difference between metrical and non-metrical kinds of songs, as well as nine distinct types of combinations of musical elements in the Murlarra song series (Anderson 1995: 14-17). Working among the Yolngu, Steven Knopoff (1992) provided an extended analysis of yuta manikay as a musical and conceptual category, and recognised four different named types of clapstick patterns: 'slow' (bulnha), 'walking' (ngarrunga), 'big' or 'important' (yindi), and 'arms' (barka) (ibid.: 148). Although he focused primary upon these named categories as referring to clapstick patterns, he did indicate that non-musical factors also play a role in the ways in which these terms are used (ibid.: 149). These studies provide a clear precedent for the analytical position adopted here, with the qualification that while different versions of a song may be most obviously associated with clapstick rhythm, the poetic and ritual dimensions may be equally important.

\section{Yiki: The knife}

To illustrate some of these interconnections and their relationships to different named versions of Dhalwangu songs, I turn now to an examination of one of the most important song subjects in the song series associated with the Dhalwangu estate at Gurrumuru: yiki, the knife. Although the historical period of contact between Yolngu and Macassan seafarers is apparent in Dhalwangu songs, this period (and the material culture associated with it) has been firmly reinterpreted within a Dhalwangu cosmological framework (see Toner 2000). As a result, songs and dances about rice, tobacco, alcohol, ships, flags, anchors, and other objects fall under the auspices of the ancestral being Birrinydji, also known as 'The Swordman'. Two separate song subjects, both called yiki (knife), refer to this implement: the first describing Dhalwangu ancestors clearing the camp at Gurrumuru using knives, and the second describing Birrinydji picking up his swords in each hand and preparing to fight. Swords and knives are among the most important symbols of Dhalwangu cultural identity.

Analysis of a 1996 performance-one that did not accompany dancereveals the ways in which different versions of this song subject develop from one to the next. This performance was essentially for entertainment and was organised by the singers themselves, who asked me to record 
it for them. In particular, they wanted to record this performance as a gift to a kinsman who was visiting Gapuwiyak. Various aspects of the performance indicated an interest in presenting a coordinated performance that showed the singers in the best possible light. This performance of the Gurrumuru Wängangur (at the camp) song series opened with 18 song items of the song subject matha (talking): 10 of the 'regular' or gumurr wanggany version, followed by four song items of a bantja or gumurr marrma version, and then four of a second bantja version. The performance then proceeded to the bulnha version of yiki, one item of which is transcribed in Figure $3 .^{4}$

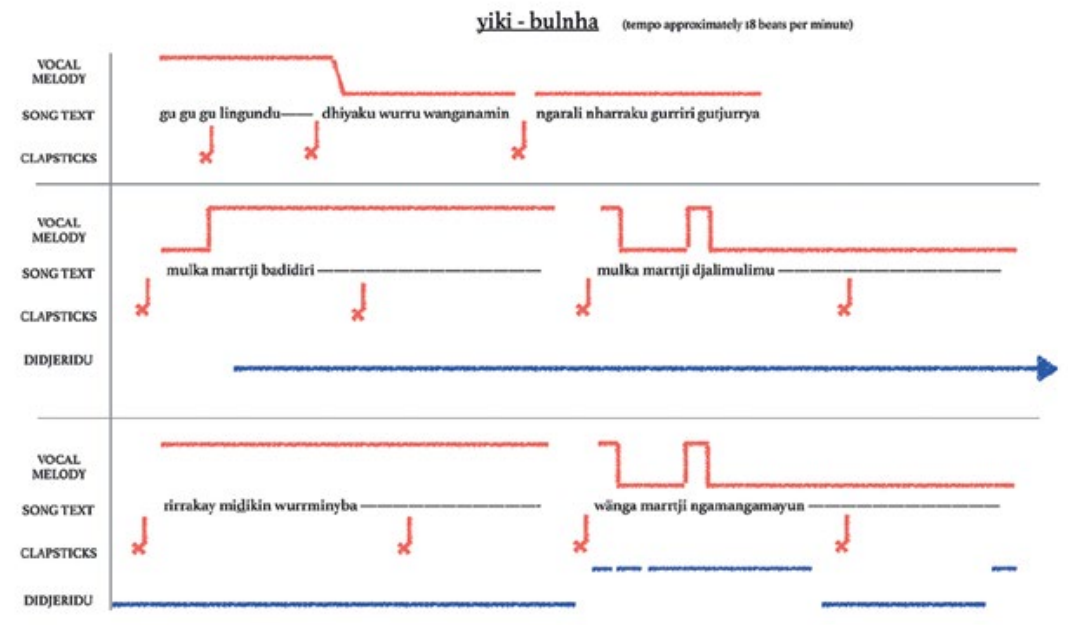

Figure 3. Bulnha version of yiki. During the performance of which this song item was a part, the singers included Bangana, Bininydjirri, Bulupal, Burumbirr, Galangarri, Lanypi, Mulyun, Munyuka, and Ngutjapuy Wunungmurra. The didjeridu accompanists included Peter Ganambarr; Djeliwuy \#2 and Raymbaki Wanambi; and Christopher, Lanypi, and Warrungu Wunungmurra

Source: Recorded by the author on 19 October 1996 in Gapuwiyak

4 In all my musical notations, the following conventions apply. The vocal melody is depicted as a set of lines representing vocal pitch, connected or broken to indicate phrasing. The absolute pitch of Dhalwangu melodies varies between and even within performances, but the relative pitch is quite consistent (see Toner 2003). For that reason, and because in this chapter I am concerned primarily with the inter-relations between musical parts rather than those parts themselves, I have opted simply to indicate relative pitch levels. The words of the song texts are placed accurately in relation to changes in pitch and phrasing, and in relation to the clapstick beats. Like the vocal melody, the didjeridu is notated only in terms of low (drone) and high (overtone) pitches, although the drone does often include an internal rhythmic pattern. A different kind of analysis than the one presented here would require different techniques of transcription and analysis. 
In this bulnha version of yiki, certain typical features of any bulnha version of any song subject are evident: a slow, rubato, and non-unison clapstick accompaniment at a tempo of around 20 beats per minute; the vocals are performed in a very free-form manner; there is no strict metrical relationship between the vocals and the clapstick accompaniment; and the didjeridu accompaniment is very smooth and unadorned, with the exception of the overtone hoots at the end that signal the end of the song item.

The song texts situate this as the initial version of the song subject, a way of introducing the song subject into the performance. After an opening $g u g u g u$ (vocables used by Dhalwangu singers to 'find the tune') and the word lingundu 'finished' (referring to the previous song subject), the singer intones dhiyaku wurru wanganamin 'this is why they talked', before singing to another man nearby ngarali nharraku gurriri gutjurrya 'give me your (half-finished) cigarette'. This vocal introduction accomplishes a number of performative ends. When a singer has decided that it is time to move on to another song subject he simply starts that subject, sometimes verbalising his decision by singing a word like 'finished' to signal to the others that the previous song subject has now concluded. The transitional phrase 'this is why they talked' links the previous song subject matha (talking) to yiki. The vocal introduction is also a place in the performance for a singer to make comments to the other performers, to give instructions to another performer, or to make a request for a drink or a cigarette, without disrupting the musical flow.

The first two textual phrases of the song item are performed across a single melodic phrase, using one of the four melodies characteristic of Dhalwangu manikay. Both textual phrases are translated as 'holding the knife while walking', using alternate names for the knife. In the next melodic phrase, with its two textual phrases, the singer evokes two images: first, the sound of the knife as it is used; and second, the idea that the knife is being used to clear the ground at the home of the Dhalwangu people. Although this particular song item does not feature a vocal coda, other performances of the bulnha version of yiki do. The bulnha version of $y i k i$ was performed three times, the third of which was spliced together seamlessly with the first song item of the yindi (big, important, or mother) version. The yindi version (characterised most clearly by a rapid clapstick accompaniment of approximately 200 beats per minute) was then performed two more times, one of which is transcribed in Figure $4 .^{5}$

5 In this notation, the representation of the clapstick pattern is not exact, but rather is representative of a continual beat at a tempo of approximately 206 beats per minute. 


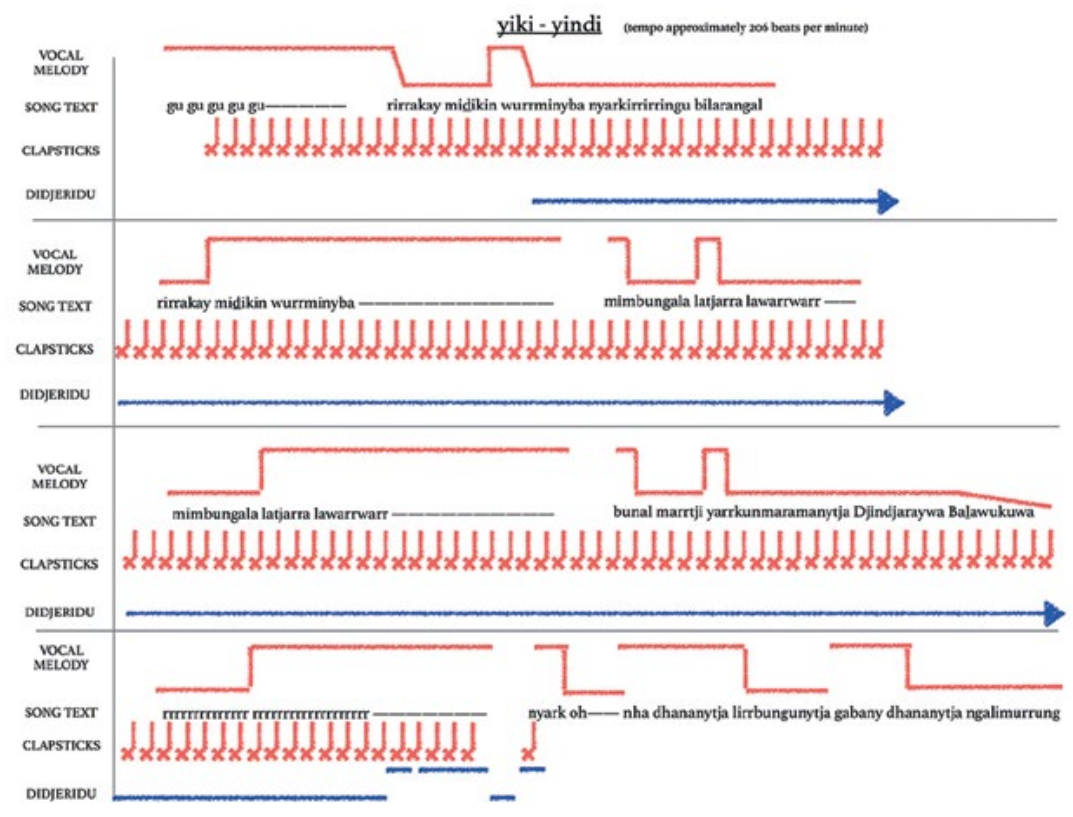

Figure 4. Yindi version of yiki

Source: Recorded by the author on 19 October 1996 in Gapuwiyak

A close analysis of the bulnha and the yindi versions reveals a number of similarities. Not only do both use the same melody, but the articulation of the song texts with the melody is identical—if one could isolate only the vocals of both versions without the clapstick accompaniment, they would sound virtually the same, both being non-metrical and even using very similar song texts. This basic vocal similarity is underscored by the fact that a bulnha song item can be seamlessly spliced on to a yindi version with only the clapsticks changing from very slow and uncoordinated to very fast and uncoordinated. The similarity is also underscored by the didjeridu accompaniment, which in both cases is smooth and unadorned by any internal pulse, unlike other versions.

The song texts of these two versions are similar, but not identical. In the bulnha version, singers emphasise that their ancestors were preparing to clear the camp with the knives, whereas in the yindi version they are described as really getting into the action. Singers make use of many different names for Gurrumuru, which is thought to be a way of 'decorating' the song to make it 'brilliant' (cf. Morphy 1989), and include likan (elbow) names that designate both ancestral people and the places 
with which they are associated. In this particular song item, the texts of the first two melodic phrases all describe the sound of the knives clearing the ground, and include the Dhalwangu likan names Djindjaray and Balawuku. Another characteristic feature of a yindi song version is that the main part of a song item concludes with a unison 'chorus' section, often representative of the sound of the song subject; in this case, the chorus is a trilled ' $r$ ' sound and a concluding 'nyark!', mimetic of the sound of the knives clearing the ground and clashing against each other. The vocal coda after the chorus asks the rhetorical question 'What is that clearing of the ground at our home?' (i.e. Why are we clearing the ground? To make our home.)

After the yindi version were three song items designated as yothu (small or child), one song item of which is shown in Figure 5. As stated above, the term yothu is used inconsistently in reference to musical structure, but it is always used in reference to a version immediately following a yindi. The most obvious difference here is that there is now a steady clapstick rhythm that has a much stricter metrical relationship with the vocal rhythm. The clapsticks start at a steady 120 beats per minute through the introduction and into the main section. A second Dhalwangu melody, the 'wurrungu $\mathrm{B}$ ', is used here, consisting of two distinct parts: a sustained higher note for the first textual phrase; and two alternating notes for the second textual phrase (these two alternating notes being identical to the ' $y u \underline{t a} \mathrm{~B}$ ' melody of the previous song versions). In this second textual phrase (comprising the second half of the melodic phrase), the steady quarter-note clapstick rhythm gives way to a quarter note-quarter rest pattern. The first half of the second melodic phrase is accompanied by a very common terminal clapstick pattern, consisting of seven quarternote clapstick beats, a single quarter rest, and a final quarter-note beat, while the second half of the melodic phrase is extended into the vocal coda. The didjeridu accompaniment, too, is different: the drone features a regular syncopated pulse produced by shaping the mouth cavity while circular breathing, and the didjeridu player uses overtone hoots to signal each upcoming change of clapstick beat. 


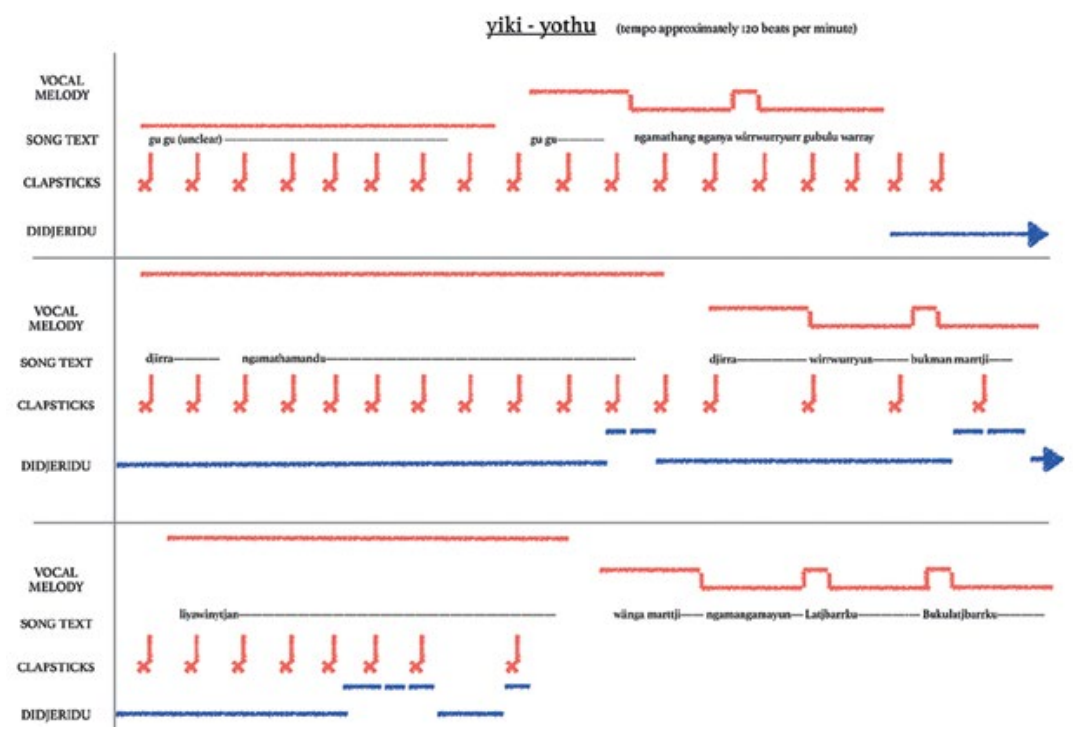

Figure 5. Yothu version of yiki

Source: Recorded by the author on 19 October 1996 in Gapuwiyak

The song texts are thematically related to the previous versions of yiki, emphasising especially the soil of Gurrumuru that is being cleared, and also things that lie beneath the soil. In another song item of this version, singers evoke narrpiya, the octopus, an important Dhalwangu symbol associated with the river at Gurrumuru. In this song item, the words ngamathamandu and ngamangamayun were both translated as 'properly', referring to correct ritual and social practices. This song item also uses the names Latjbarrk and Bukulatjbarrk, both likan names for the Warramiri people who are co-owners of the Birrinydji cosmology.

Following the yothu version, the singers performed three song items of the bantja (arm) version (Figure 6). In addition to providing a variant rhythm when accompanying danced performances, the bantja is also said to be performed as a way of bringing a song subject to its proper conclusion before moving on to the next song subject. Once again, the clapsticks (c. 90 beats per minute) provide a steady rhythm, this time a three quarter note/one quarter rest pattern, and the relationship between the clapsticks and the vocals is metrical ( 16 beats per melodic phrase, divided equally between two textual phrases). In this particular song item, the main elements highlighted in the song text are a number of different names for 
the Dhalwangu ancestral estate at Gurrumuru; in other song items in this performance, other imagery describes the sounds of the knives going into the jungle at Gurrumuru (where Birrinydji is said to live).

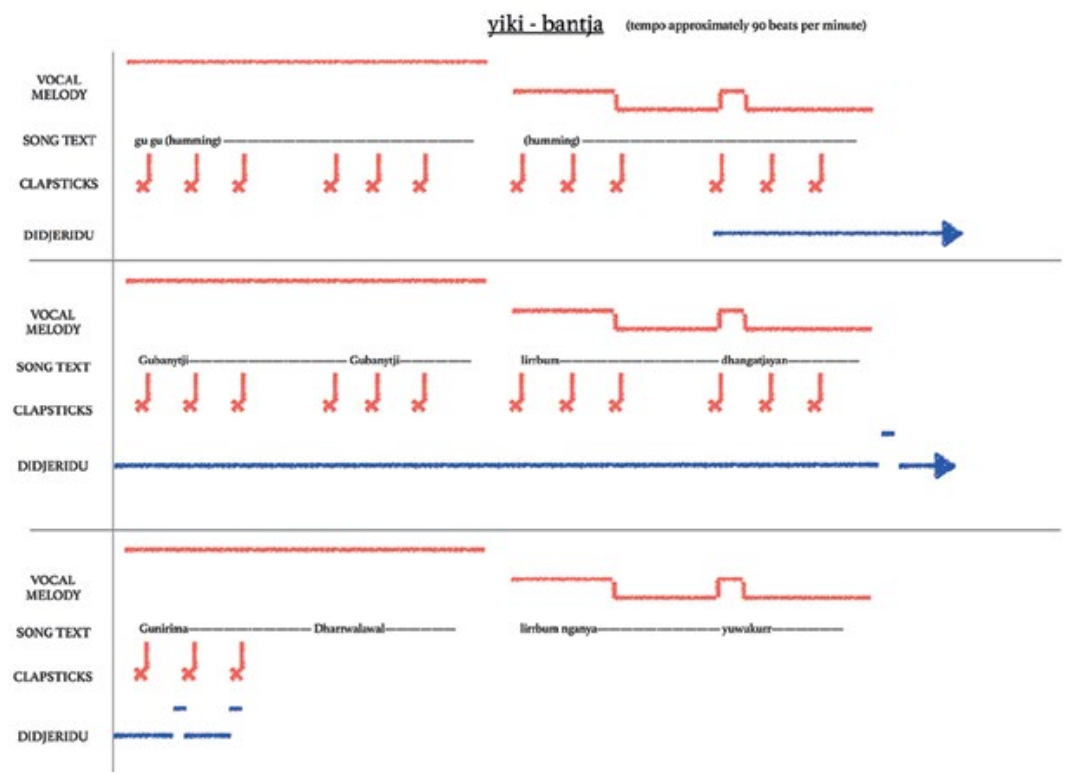

Figure 6. Bantja version of yiki

Source: Recorded by the author on 19 October 1996 in Gapuwiyak

The performance finished with two yuta (new) song items of $y i k i$, one of which is transcribed in Figure 7. The yuta manikay (cf. Knopoff 1992) is based on an ancestral song subject that already exists in a group's repertoire, but is related metaphorically to some contemporary event. The song texts of yuta manikay are similar to other versions, except for two unison 'chorus' sections that use language that refers to the contemporary event. A yut $a$ version is spoken about, and often functions as, a bantja version, 'finishing off a subject before moving on to the next, an equivalence also noted by Knopoff (1992: 149) when he states that the clapstick patterns associated with yuta manikay are always categorised as barka ('arms'). Rhythmically, this version of yiki is similar to the yothu and bantja versions in that there is a slow but steady clapstick rhythm (67 beats per minute) and a metrical relationship between clapsticks and vocals. A unique rhythmic feature of some yuta versions evident here is that singers beat a single clapstick on the ground (represented by a circular note head) instead of beating them together (represented by an ' $\mathrm{x}$ ' note head). Each melodic phrase is 16 beats long, eight beats on the top note, 
and eight beats on the two alternating lower notes. The introduction consists of a repeated ya_lilililili__ said to be mimetic of the sound of the knives hitting each other rapidly. The first textual phrase describes Dhalwangu ancestors clearing the ground while moving; the second textual phrase asks the rhetorical question 'Why do we clear the ground? (to make our camp)'.

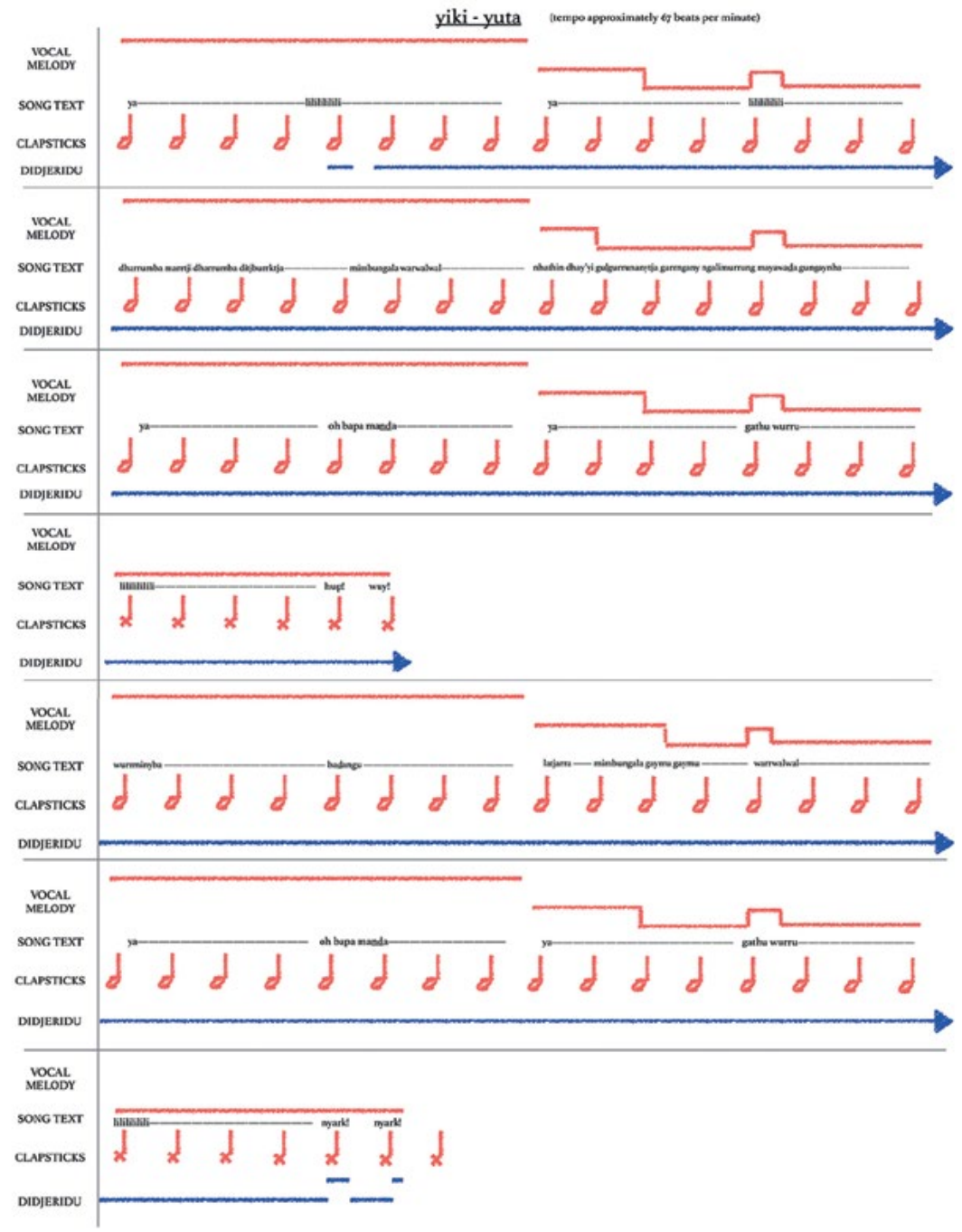

Figure 7. Yuta version of yiki

Source: Recorded by the author on 19 October 1996 in Gapuwiyak 
The next melodic phrase accompanies the unison 'chorus' section: yaoh bapa manda, ya_ gathu wurru, lilililili_ nyark! nyark! This refers to the composer's two 'fathers', both deceased, who appeared to him in a dream holding knives in their hands; ' $y a$ ' is an expression of sympathy, concern, or worry. Both textual phrases of the next melodic phrase consist entirely of alternate names for the ancestral knife, followed by a second 'chorus' section. In a second song item of this version, one singer very forcefully sang 'bup! wuy! instead of 'nyark! nyark! at the end of the chorus, which is the vocable used by dancers when this song is performed.

Each of these 'versions' is a representation of the 'same' song, yiki, but Dhalwangu musical theory distinguishes between them based on their function and meaning. They are clearly distinguishable from one another by their musical features, and yet the musical features of one version frequently overlap with those of another. Most significantly for the present analysis, however, is the fact that they demonstrate the 'variable rules' and 'variable but consistent structures' that Clunies Ross and Wild noted in their characterisation of such performances as 'formal'.

As discussed above, one 'variable but consistent structure' evident in all of my documented field recordings of Dhalwangu music is the fact that musicians proceed from one version of a song subject to another in a welldefined order: bulnha $\rightarrow$ yindi $\rightarrow($ yothu $) \rightarrow$ 'regular'/gumurr wanggany $\rightarrow$ bantjal gumurr marrma $\rightarrow$ yuta . Every song subject does not necessarily have every version. For example, the bulnha and yindi versions are usually reserved for song subjects that are considered to be especially important or sacred, and the yothu version is an alternate designation that can be applied to either a gumurr wanggany or a gumurr marrma version. Also, on a given occasion a singer may decide to skip one or more versions of a song subject for any of a variety of reasons. The order set out above, however, is virtually always followed. ${ }^{6}$ The only exceptions that I am aware of are a few instances in which a yuta version of a song subject was followed by a bantja version. This can be explained, in part, by the ways in which singers talk about yuta manikay as 'like a bantja' in that they are used to

6 Anderson also noted a consistent order in proceeding from one 'Type' to another in song subjects that have more than one 'Type', including the recognition that his 'Type 9 (ngarkana)' song items (which appear from his descriptions to be the same as the yindi described here) always precede other 'Types' of song items of the same song subject (Anderson 1995: 17). 
complete a subject's narrative and are therefore somewhat interchangeable. But I am not aware of any case where a bulnha version was performed after a yindi, or a gumurr marrma preceded a gumurr wanggany.

The ordering of song versions is, in part, related to ritual considerations, including the role of dancers in performances. In Yolngu rituals, certain key episodes are marked by a heightened and very specific kind of ritual action involving both song and dance, and usually the calling out of $\underline{l} i k a n$ names by a djirrikay or ritual specialist. In Knopoff's analysis of Yolngu manikay, he also noted this 'periodic ceremonial event' called gunbur'yun (1997: 46), known as birkarr'yun for Yirritja ceremonies. This may be similar to Clunies Ross and Wild's identification of certain occasions during Anbarra mortuary ceremonies in which 'dance is a prescribed accompaniment to a specific stage in the ritual', such as the placing of a deceased person's bones in a hollow log coffin (Clunies Ross and Wild 1984: 212). In the Yolngu case, such episodes include announcing a death (called bäpurru ngäma, lit. 'death hear'), moving a corpse, marking a gravesite, and bringing a newly arrived group of kin to visit a deceased person lying in state (called bäpurru djirribum 'showing your sadness for the body').

In my experience, these ritual episodes typically begin with a number of bulnha song items $s^{7}$ of an appropriate song subject, with singers leading a group of dancers toward the location that is the focus of the episode. The dancers move deliberately forward making ritual calls (in time with the slow clapstick beat), and a djirrikay may call out likan names. After the bulnha song items, singers may then change to another version of the song subject, which can involve a changed role for the dancers. When announcing a death, for example, singers switch to the yindi version of the song subject, while the identity of the deceased is announced to the gathered women and children (in fact, the identity of a deceased person should never be revealed until a yindi song version has been performed). When a gravesite is to be marked with the red flags that are important Dhalwangu symbols, the flagpoles are rolled back and forth on the ground in time to the slow, deliberate clapstick beats of the bulnha versions of the garrurru (flag) song subject while the dancers, squatting on the ground

7 According to Knopoff (1997: 46), songs that culminate in gunbur'yun are usually yindi manikay. Among the Dhalwangu, it is certainly very common for birkarr'yun (gunbur'yun) to be associated with a yindi song version, although in some cases (as shown in Figure 8) the correct version is bulnha, and on other occasions singers begin with a bulnha and then transition into a yindi version. 
on either side of the flagpoles, intone 'Oh Allah, oh Allah'. After several bulnha song items, the singers switch to a faster gumurr wanggany version of garrurru; the leading dancers raise the flagpoles into the air and unfurl the flags, and all of the dancers move rhythmically forward toward the gravesite in time to the steady clapstick beat, again intoning certain appropriate ritual calls. The switch from one version of the song subject (usually the bulnha version) to some other version always proceeds in the order outlined above.

The coordination of musical structure with the involvement of dancers and ritual specialists is exemplified by a ritual episode, like the ones described above, from a funeral that took place in Gapuwiyak in 1996. The song subject is, once again, yiki, transcribed in Figure 8. The important and sacred nature of the yiki song subject, and specifically its bulnha version, is indicated by the use of this particular four-tone Dhalwangu melody that is only ever used with such song subjects on such occasions. As is typical of bulnha versions, the clapstick beat is very slow, deliberate, and not in strict unison, although there is some coordination here of four clapstick beats for every melodic phrase (or two for each textual phrase). ${ }^{8}$ The didjeridu played a smooth, steady drone, adorned only by overtone hoots to signal the end of the song item. The dancers play an important role here in providing ritual calls that they use to accompany their very deliberate movements, first a long trilled rrrrrrrr__ before calling out nyark! in time with the clapstick beats. As discussed above, both of these calls are said to represent the sound of the knives clashing together as they were used by Dhalwangu ancestors to clear the camp, and in fact the dancers very often have swords and machetes in their hands during these performances. The swords and machetes are struck together in time with the clapsticks and the nyark! calls. Also notable in this transcription is the calling out of likan names by a ritual specialist or djirrikay, timed with every other clapstick beat in the middle of the song item. All of these different performative elements, taken together, indicate a close inter-relation of melody, rhythm, and the actions of the dancers, one that validates Clunies Ross and Wild's analyses.

8 Although the song texts of this recording were not transcribed and translated, it is possible to identify certain words and phrases used by the singers in this performance that were also used in the performance of yiki discussed above. 


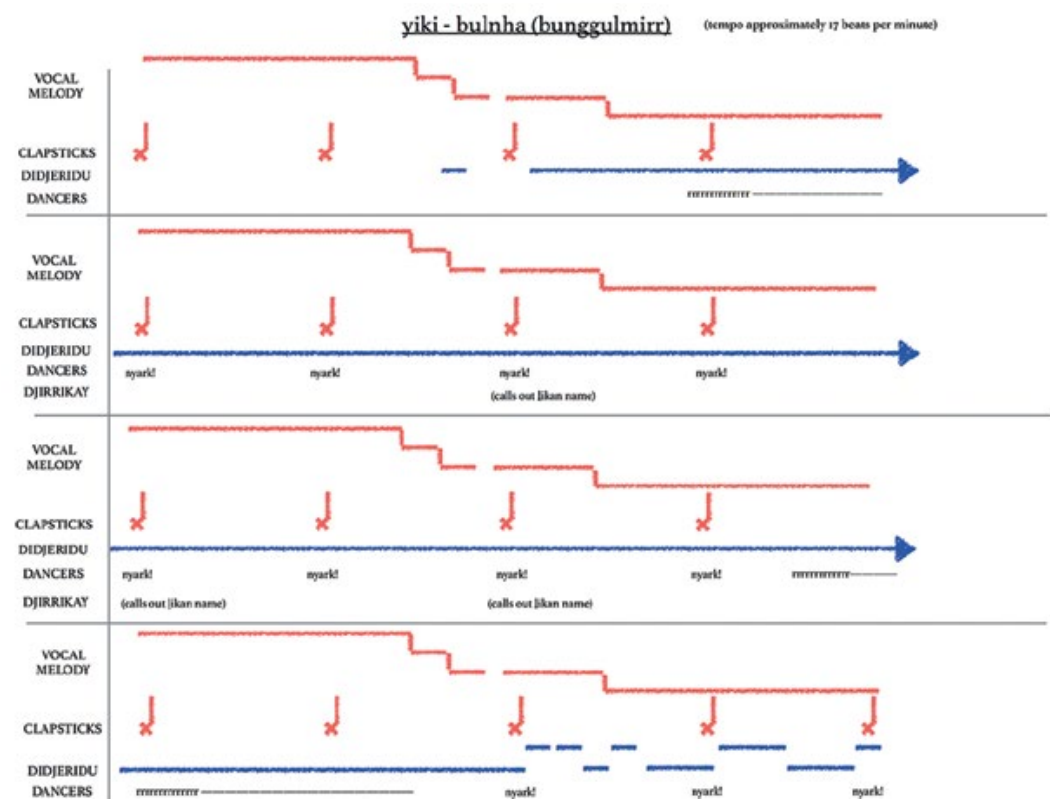

Figure 8. Bulnha version of yiki in a danced performance. During the performance of which this song item was a part, the singers included Bandipandi, Bangana, Bininydjirri, Bulupal, Burumbirr, Mulyun, Multhangdul, and Ngutjapuy Wunungmurra; and Gambali Ngurruwuthun. The didjeridu accompanists included Lanypi Wunungmurra and Raymond Guyula

Source: Recorded by the author on 30 March 1996 in Gapuwiyak

Nevertheless, the potential impact of dance is felt even in the (more frequent) performances of manikay in which there is no dancing, known as ngaraka (bones). In the very structuring of different versions of a song subject, the shadow of dance is implicit. The gumurr wanggany and gumurr marrma versions, which are taken to mean 'number one' and 'number two', are intended to provide at least two different, strictly metrical musical settings for two distinctive sets of dance movements. The first gumurr wanggany version is often more straightforward, and the second gumurr marrma version more elaborate, in order to provide variety for the dancers and showcase their virtuosity. Changes in clapstick rhythm within a given version are signalled by overtone hoots on the didjeridu, ostensibly to provide dancers with forewarning of their own coordinated change in dance step (although it is more common for the lead dancer to provide the musicians with cues). Yuta manikay, too, seem designed with potential dance accompaniment in mind, with a wide range of changing clapstick 
patterns to accompanying changes in dance steps. In Figure 7 above, we can also see a direct reference to dance performance even though there was no dancing on this occasion: in the unison 'chorus', the usual lililililinyark! nyark! was replaced by one young singer with lilililili_ bup! wuy!, a vocal call used specifically by dancers in a number of different song subjects. So it seems clear that what I have called Dhalwangu musical theory is one that also includes a parallel choreological theory.

\section{Conclusions}

The intricacies of clapstick rhythms and patterns have been something of a 'growth area' in Australian Aboriginalist ethnomusicology for more than 20 years, but especially in the past decade. Building on the insights of scholars like Anderson and Knopoff, mentioned above, other scholars have focused great analytical attention on 'rhythmic modes' in a wide variety of Aboriginal music traditions and their overall significance within wider linguistic, textual, and musical structures (see, for example, Treloyn 2014; Marett, Barwick, and Ford 2013; Marett 2005; and Barwick 2003). This is a clear indication not only of the richness of clapstick rhythm as a source of insight into Aboriginal musical structures, but also of the interconnectedness of rhythm, text, melody, and other performative elements in Aboriginal musical traditions. Stephen Wild's research on Anbarra music and dance laid an extremely important foundation upon which these studies have been built.

Beyond the recognition and close analysis of these performative interconnections, which is valuable in its own right, in this chapter I have suggested another area worthy of close attention: that is, the idea that our interlocutors are not merely virtuosos, but are also music theorists. There is no doubt that effective musical performances require singers who have a vast store of poetic images and song texts upon which they can draw, as well as the ability to switch nimbly from one rhythmic setting to another at appropriate moments in a ritual, as well as dancers who convincingly embody the essence of ancestral beings, didjeridu players who can provide subtle accompaniments and pulsing grooves, and knowledgeable ritual specialists who coordinate it all with a comprehensive knowledge of ritual protocols. My ongoing research on Dhalwangu 'song versions' has indicated to me that there is more than skill at work here. There is also a detailed and systematic theory of musical structures. My Dhalwangu 
informants did not merely extemporise in the moment of performance on the basis of 'variable rules' and 'variable but consistent structures'. They intellectualised about their music in a wide variety of contexts, including many contexts set apart from actual performances; they developed a kind of analytical metalanguage (cf. Keen 1995) that they used to situate their music not only within their broader cultural and social context, but also as part of an analytical conversation with me. So, although this area of my research began with clapstick patterns, it is no longer merely about rhythm.

I have Stephen Wild to thank for this, as the scholar who most influenced my approach to musical analysis. As Aboriginal music research continues to develop into the twenty-first century, I have no doubt that articles like 'Formal Performance' will continue to have a lasting impact.

\section{References cited}

Anderson, Greg. 1995. 'Striking a Balance: Limited Variability in Performances of a Clan Song Series from Central Arnhem Land.' In The Essence of Singing and the Substance of Song: Recent Responses to the Aboriginal Performing Arts and Other Essays in Honour of Catherine Ellis, edited by Linda Barwick, Allan Marett, and Guy Tunstill, 12-25. Sydney: University of Sydney.

Barwick, Linda. 2003. 'Tempo Bands, Metre and Rhythmic Mode in Marri Ngarr "Church Lirrga" Songs.' Australasian Music Research 7: 67-83.

Butler, Bryan, and Stephen A. Wild. 1981. Djambidj: An Aboriginal Song Series from Northern Australia. Performed by Frank Gurrmanamana and Frank Malkorda (singers) and Sam Gumugun (didjeridu accompanist). One 33 1/3 rpm disc. AIAS 16. Canberra: Australian Institute of Aboriginal Studies.

Clunies Ross, Margaret. 1978. 'The Structure of Arnhem Land SongPoetry.' Oceania 49 (2): 128-56. doi.org/10.1002/j.1834-4461.1978. tb01383.x. 
Clunies Ross, Margaret, and Stephen A. Wild. 1982. Djambidj: An Aboriginal Song Series from Northern Australia. Companion book to $331 / 3 \mathrm{rpm}$ disc of same title. Canberra: Australian Institute of Aboriginal Studies.

- 1984. 'Formal Performance: The Relations of Music, Text and Dance in Arnhem Land Clan Songs.' Ethnomusicology 28 (2): 209-35. doi.org/10.2307/850758.

Keen, Ian. 1995. "Metaphor and the Metalanguage: "Groups" in Northeast Arnhem Land.' American Ethnologist 22 (3): 502-27. doi.org/10.1525/ae.1995.22.3.02a00030.

Knopoff, Steven. 1992. 'Yuta Manikay: Juxtaposition of Ancestral and Contemporary Elements in the Performance of Yolngu Clan Songs.' Yearbook for Traditional Music 24: 138-53. doi.org/10.2307/768475.

- 1997. 'Accompanying the Dreaming: Determinants of Didjeridu Style in Traditional and Popular Yolngu Song.' In The Didjeridu: From Arnhem Land to Internet, edited by Karl Neuenfeldt, 39-67. Sydney: John Libbey.

Marett, Allan. 2005. Songs, Dreamings and Ghosts: The Wangga of North Australia. Middletown, CT: Wesleyan University Press.

Marett, Allan, Linda Barwick, and Lysbeth Ford. 2013. For the Sake of a Song: Wangga Songmen and Their Repertoires. Sydney: University of Sydney Press.

May, Elizabeth, and Stephen A. Wild. 1967. 'Aboriginal Music on the Laverton Reservation, Western Australia.' Ethnomusicology 11 (2): 207-17. doi.org/10.2307/849819.

Morphy, Howard. 1989. 'From Dull to Brilliant: The Aesthetics of Spiritual Power among the Yolngu.' Man, n.s., 24 (1): 21-40. doi.org/ $10.2307 / 2802545$.

Moyle, Alice. 1978. Aboriginal Sound Instruments. Canberra: Australian Institute of Aboriginal Studies.

Toner, P. G. 2000. 'Ideology, Influence and Innovation: The Impact of Macassan Contact on Yolngu Music.' Perfect Beat 5 (1): 22-41. 
__. 2003. 'Melody and the Musical Articulation of Yolngu Identities.' Yearbook for Traditional Music 35: 69-95. doi.org/10.2307/4149322.

Treloyn, Sally. 2014. 'Cross and Square: Variegation in the Transmission of Songs and Musical Styles between the Kimberley and Daly Regions of Northern Australia.' In Circulating Cultures: Exchanges of Australian Indigenous Music, Dance and Media, edited by Amanda Harris, 203-38. Canberra: ANU Press.

Wild, Stephen A. 1986. ed. Rom: An Aboriginal Ritual of Diplomacy. Canberra: Australian Institute of Aboriginal Studies. 
This text is taken from A Distinctive Voice in the Antipodes: Essays in Honour of Stephen A. Wild, edited by Kirsty Gillespie, Sally Treloyn and Don Niles, published 2017 by ANU Press, The Australian National University,

Canberra, Australia.

dx.doi.org/10.22459/DVA.07.2017.03 